\title{
Ekonomik Koordinasyon Bağlamında Enflasyon Hedeflemesi ve Mali Disiplin İlişkisi: Türkiye Örneği
}

Hilmi ÇOBAN, Department of Public Finance, Faculty of Economics and Administrative Sciences, Kirikkale University, Turkey; e-mail: hcoban20@gmail.com

\section{Economic Coordination in the Framework of the Relationship between Inflation Targeting and Fiscal Discipline: The Case of Turkey}

\begin{abstract}
Ensuring economic coordination is very important in terms of managing the macro economic impact of policies. Coordination of monetary and fiscal policy in terms of the basic policy of macro-economic effects has been emphasized more than in recent years. In this study, within the framework of the coordination of monetary and fiscal policy will focus on the need for economic coordination and find a wide range of applications in recent years, the relationship between inflation targeting and fiscal discipline will attempt to demonstrate using Granger causality analyses and Turkish treasury and Central bank monthly data from the 2006-2014 years.

Keywords

Economic Coordination, Monetary Policy, Fiscal Policy, Inflation Targeting.

JEL Classification Codes : E61, E52, E31.

$\ddot{\mathbf{O} z}$

Ekonomik koordinasyonun sağlanması, makroekonomik etkileri olan politikaların yönetilmesi bakımından oldukça önemlidir. Makroekonomik etkileri bakımından en temel politikalardan olan para ve maliye politikalarının koordinasyonu son yıllarda daha fazla vurgulanmaktadır. Çalışmada para ve maliye politikalarının koordinasyonu çerçevesinde ekonomik koordinasyonun gereklilikleri üzerinde durulacak ve son yıllarda geniş uygulama alanı bulan enflasyon hedeflemesi ile mali disiplin arasındaki ilişki Türkiye'nin 2006-2014 yılları arasındaki hazine müsteşarlığı ve merkez bankası aylık verileri kullanılarak Granger nedensellik analiziyle ortaya konmaya çalışılacaktır.
\end{abstract}

Anahtar Sözcükler $\quad$ : Ekonomik Koordinasyon, Para Politikası, Maliye Politikası, Enflasyon Hedeflemesi. 


\section{Giriş}

Son y1llarda gelişmiş ve gelişmekte olan ülkelerin para otoriteleri tarafindan enflasyon hedeflemesi sistemi temel para politikası rejimi olarak kullanılmaktadır. Fiyat istikrarını sağlama nihai hedefine yönelik olarak uygulanan enflasyon hedeflemesi sisteminin kullanımının genişlemesi, diğer politikalar ile olan ilişkisini daha önemli hale getirmektedir.

Enflasyon hedeflemesi sistemi merkez bankalarının bağımsızlığı ile birlikte daha fazla ön plana çıkan bir uygulama olmakla birlikte, ortaya konan enflasyon hedefinin tutturulabilmesi açısından makroekonomik etkileri olan başta maliye politikası olmak üzere diğer politikaların da söz konusu hedefi engelleyici değil, destekleyici olmalarını beklenmektedir.

Para ve maliye politikalarının farklı amaçlara sahip olmaları beklenmektedir. Ancak politikaların amaçları arasında çıkan çatışma nedeniyle uygulana politikaların etkinliklerinin azalması, koordinasyon açısından ortaya konan temel problemlerden biridir. Bu bakımdan merkez bankasının bağımsızlığı enflasyon hedeflemesi sistemini uygulayan 30 ülke için önemli olmakla birlikte, bu bağımsızlık nedeniyle ortaya çıkan koordinasyon sorunları da vurgulanmaktadır.

Çalışmanın ilk bölümünde ekonomik koordinasyon para ve maliye politikaları özelinde gerekçeleri ile birlikte ortaya konulmaktadır. Teorik olarak para politikası rejimi olarak ortaya konan enflasyon hedeflemesi sistemi ve maliye politikasının temel çıktılarından biri olan mali disiplinin ardından Türkiye'de 2006-2014 yılları arasındaki veriler kullanılarak bu ilişki somut olarak değerlendirilecektir.

\section{Ekonomik Koordinasyon}

Demokratik ülkelerde modern yönetim sürecinin temel konularından biri olarak kamu politikalarının koordinasyonu, araştırmacıların ilgisinin yoğunlaştığı alanlardan biridir. Etkinliği olmayan programların azaltılarak uygulanan programlara yönelik etkinlik düzeyinin arttırılabilmesi için ülkeler kurumlar arası koordinasyona önem vermektedir (Matei \& Dogaru, 2013: 66). Ülkeler tarafından yürütülen kamu politikaları toplumsal tercihlerin farklılığı, toplumsal ve ekonomik yapıdaki değişim ve hatta teknolojik ilerleme ile birlikte farklılaşmış, çeşitlenmiş ve daha karmaşık bir yapıya bürünmüştür. Aynı toplumsal hedefe yönelik uygulanan farklı kamu politikaları arasında eşgüdümün sağlanmasının, hedefin gerçekleşmesine yönelik olasılıkları arttırması ve bütün bu süreç sonunda uygulanan kamu politikalarının etkinliğinin artması beklenmektedir. 
Politika koordinasyonu para ve maliye politikalarının koordinasyonunu ifade etmektedir ve bunun dar anlamdaki ifadesi, fiyat istikrarını zaafa uğatacak uygulamaların önlenmesidir. Daha geniş bir ifade ile politika koordinasyonu, ülkeler için ortaya konmuş olan ortak hedefler doğrultusunda gerekli uygulamaların hayata geçirilmesini ifade etmektedir (Ferre, 2008: 223). Politika koordinasyonu geniş anlamda ele alındığında, yalnızca bir ülkenin özellikle para politikası hedeflerine uygun biçimde para ve maliye politikalarının koordinasyonunu değil, uluslararası entegrasyonlar ve entegrasyona dâhil olan ülkeler açısından ele alınmasını gerektirmektedir. Ancak çalışmamızın kapsamı, ülke içinde uygulanan para ve maliye politikalarının koordinasyonunu ifade edecek şekilde belirlenmiştir.

Ekonomik büyümenin sağlanması, fiyat istikrarı ve ödemeler dengesinin sağlanması gibi makroekonomik hedefler, söz konusu politikaların uygulayıcıları arasındaki koordinasyonun önemini arttırmaktadır. Makroekonomik hedeflere yönelik politikaların etkinliği, yalnızca kendi amacına yönelik sonuçlar ile değil, söz konusu politikanın diğer alanlar üzerindeki etkisi ile de değerlendirilmelidir (Laurens \& Piedra, 1998: 5). Politika uygulayıcılar sorumlu oldukları politikalar ile ilgili olarak, kendi uygulamalarının sonuçlarını değerlendirirken, diğer politikalar ile karşılıklı etkileşimi göz önünde bulundurmak durumundadır. Politikalar arası etkileşimin, etkinlik üzerinde olumlu veya olumsuz etki oluşturabilmesi politikalar arasındaki koordinasyona ilişkin beklentileri artırmaktadır.

Ekonomi politikasına ilişkin araçlar temel olarak parasal ve mali araçlar olmak üzere iki gruba ayrılabilir. Para otoritesi olarak genellikle merkez bankaları tarafından uygulanan para politikası araçları ile maliye bakanlığı tarafından yürütülen maliye politikası araçlarının belli bir işbirliği içinde yürütülmesi zorunludur (Hanif \& Arby, 2003: 1). Bu zorunluluğun arkasındaki temel neden her iki politikanın ulaşmak istediği amaçlar arasında uyumun sağlanmasının gerekli olmasıdır. Her iki politika için ortaya konan hedefler çoğu kez ortak olmakla birlikte, politikaların koordinasyonuna ilişkin yaşanan asıl sorun, amaçlar arasında çatışmanın olduğu politikalar arasında koordinasyonun sağlanmasıdır. Bu durumda öncelik sırasının belirlenmesi gerekmekte ve firsat maliyeti ortaya çıkmaktadır.

Para ve maliye politikalarının koordinasyonuna ilişkin yapılan açıklamalar doğrultusunda, para ve maliye politikaları arasında yapılacak bir koordinasyonun gerekçelerini Laurens ve Piedra (1998) aşağıdaki şekilde sıralamıştır (Laurens \& Piedra, 1998: 5-6)

- $\quad$ Ekonomik koordinasyon, finansal istikrarın sağlanmasına, yüksek faiz, döviz kuru baskısı ve yüksek enflasyonun önlenmesine katkı sağlayarak sürdürülebilir bir ekonomik büyümeyi sağlayabilir, 
- Politika koordinasyonu ile para ve maliye politikaları arsındaki zaman gecikmesi problemi ortadan kaldırılabilir.

- Ekonomik koordinasyon, para ve maliye politikalarını etkinliğini ve başarısını arttıracaktır.

- Koordinasyon ile makro ekonomik performans yukarıya doğru çıkacaktır.

- Nordhaus (1994) Nash dengesi yardımı ile ortaya koyduğu çalışmasında, koordinasyon ile bütçe açıklarının azalacağını ve yüksek faizlerin düşeceğini belirtmiştir (Nordhaus, 1994: 150).

- Halaç (2007) özellikle mal ve sermaye akımlarının serbest olduğu ekonomilerde koordinasyonun sürdürülebilir bir ekonomik büyüme, fiyat istikrarı ve ödemeler bilançosunda denklik için gerekli olduğunu belirtmiştir (Halaç, 2007: 34).

- Para ve maliye politikalarının koordinasyonu deflasyonist şoklarla mücadelede olumlu katkı sunabilecektir (Eggertsson, 2010: 2).

- Para maliye politikaların arasında koordinasyonun yokluğu, toplumsal refahın azalmasına neden olacaktır (Blinder, 1982: 8).

Para ve maliye politikalarının koordinasyonuna ilişkin sayılan gerekçelerin genel yaklaşımı koordinasyonun yokluğunda ortaya çıkabilecek sorunlar üzerine yoğunlaşmalarıdır. Bu noktadan hareketle koordinasyon ile politikaların etkinliğinin artması, ekonomik performansın yükselmesi ve sosyal refahın arttırılması gibi katkılarının olması beklenmektedir.

Gelişmiş ve gelişmekte olan birçok ülkede son yirmi yılda para politikası rejimi, enflasyon hedeflemesi sistemi üzerine kurulmaktadır. Türkiye'nin de para politikası rejimi olarak kendisine seçtiği bu sistem, politikanın etkin biçimde uygulanabilmesi bakımından maliye politikası ile iç içedir. Maliye politikasının kullandığı araçlardan birisi olarak mali disiplinin sağlanması, merkez bankaları tarafından uygulanan enflasyon hedeflemesinin etkinliğini doğrudan etkilemekte ve bu nedenle maliye politikaları ile uyumlu çalışması ön şart olarak ortaya konmaktadır.

Politikalar arasında sağlanacak koordinasyon, para ve maliye politikalarının başarısı ve her iki politikanın karşılıklı olarak birbirine katkısı açısından son derece önemlidir. Para ve maliye politikasının koordinasyonu, politikaların kısa dönemli uyumlarını ifade etmekle birlikte, makroekonomik performans üzerinde etkili olacak şekilde uzun dönemli olarak da analiz edilebilir (Laurens \& Piedra, 1968: 6). Para ve maliye politikalarının esasen temel hedefi makroekonomik performansa olumlu yönde katkı 
sağlayabilmektir. Bu nedenle politikalar arasındaki koordinasyonu uzun dönemli olarak ele almak, bu bağlamda koordinasyona yönelik olarak ortaya konan uygulamaların bu makroekonomik hedeflere uygun olmasına odaklanmak oldukça önemlidir.

Esasen ekonomik koordinasyon, makroekonomik hedeflere odaklanmış bütün politikaların uyumlu ve koordineli biçimde uygulanmasını ifade etmekte iken, genel olarak para ve maliye politikalarının koordinasyonu üzerine odaklanılmaktadır. Bu bağlamda ülkemizde de para politikası rejimi olarak uygulama alanı bulan enflasyon hedeflemesi ile maliye politikasının en önemli amaçlarından olan mali disiplin arasındaki ilişki ele alınmaya çalışılacaktır.

\section{Enflasyon Hedeflemesi ve Mali Disiplin İlișkisi}

Enflasyon hedeflemesi hükümet, merkez bankası veya her ikisinin birlikte belirlediği ve kamu oyuna ilan ettiği spesifik sayısal bir enflasyon hedefinin veya sayısal bir enflasyon hedef aralığının sağlanması için merkez bankasının çalışmasıdır (Bernanke \& Mishkin, 1997: 98). Enflasyon hedeflemesi rejimi, merkez bankasının kendisine nihai hedef olarak seçtiği fiyat istikrarının sağlanması amacı ile ilgili olarak sayısal olarak kendisine bir enflasyon hedefi belirlemesi ve bunu kamuoyuna açıklaması şeklinde uygulama alanı bulan bir para politikası rejimidir (Alparslan \& Erdönmez, 2000: 16). Enflasyon hedeflemesi sisteminde nihai hedefe yönelik olarak uygulanan ara hedefler yerine, doğrudan sayısal bir enflasyon oranı veya aralığı belirlenmekte ve kamuoyu ile paylaşılan bu hedefe yönelik para politikaları uygulanmaktadır. Esasen bu sistemde hedeflenen enflasyon oranı, bizatihi nihai hedefin kendisi olmaktadır. Ortaya konan enflasyon hedefinin belli bir sayı olmasının yanı sıra, belli bir aralık olarak da seçilebilmektedir. Merkez bankası kamuoyuna ilan edilen hedefin yakalanabilmesi veya hedeften uzaklaşılmaması için elindeki politika araçlarını kullanırken en çok tercih ettiği araç kısa vadeli faiz oranlarıdır.

İlk kez 1990 yılında Yeni Zelanda'da, onu takiben 1991 yılında Kanada'da ve 1992 y1lında İngiltere'de uygulanan enflasyon hedeflemesi sistemi son yıllarda oldukça popüler hale gelmiştir (Gosselin, 2007: 2). Enflasyon hedeflemesi sistemi bugün 30 merkez bankası tarafından uygulanan ve popülerliği sürekli artan bir para politikası rejimidir (Roger, 2009: 6). Ülkemizde de enflasyon hedeflemesi sistemi 2002 yılından itibaren uygulama alanı bulmuş, ancak henüz sistemin gerekliliklerinin sağlanamaması ve ekonominin istikrarlı bir yapıya kavuşabilmesi için enflasyon hedefi kamuoyuna ilan edilmemiş ve örtük enflasyon hedeflemesi biçiminde uygulanmıştır. 2006 yılından itibaren ise para politikası rejimi olarak kullanılan enflasyon hedeflemesi sistemi kamuoyuna ilan edilmiş ve açık enflasyon hedeflemesi şeklinde uygulanmıştır. Dennis (2010) ve Sherwin (2000) enflasyon hedeflemesi yaklaşımında sayısal enflasyon hedefinin veya aralığının kamuoyuna açıklanmasını ve tüm para politikalarının bu hedefe yönelik formüle edilmesini gerekli bir 
şart olarak belirtmektedir (Dennis, 2010; Sherwin, 2000: 3). Bu bağlamda Türkiye'de enflasyon hedeflemesi sisteminin 2006 yılından itibaren uygulama alanı bulduğu söylenebilir.

Enflasyon hedeflemesi, para politikasını nihai hedefi olan fiyat istikrarının sağlanmasına ve sürdürülmesine yönelik modern bir para politikası rejimidir (Şahin, 2014: 116). Mishkin (2000) ve Mishkin ve Savastano (2000) enflasyon hedeflemesinin temel çerçevesini şu şekilde belirtmişlerdir. Sayısal bir enflasyon hedefinin kamuoyuna deklare edilmesi; politikanın fiyat istikrarı üzerine oturması; etkin bir bilgilendirme servisinin kullanılması ve yüksek seviyede hesap verebilirliğin ve şeffaflığın olması (Amato \& Gerlach, 2002: 782). Bu kriterler enflasyon hedeflemesi sisteminin anlaşılabilmesi için gerekli çerçeveyi ortaya koyması bakımından oldukça önemlidir. Enflasyon hedeflemesi sisteminde merkez bankasından daha şeffaf, hesap verebilir olması beklenmekte, sayısal hedefin kamuoyuna sunulmasından başlayarak, bu sayısal hedefe ulaşmak için uygulanan politika süreçlerinde şeffaflık ve hesap verebilirliğin önemine vurgu yapılmaktadır.

Teorik çalışmalar ve bu teorik çalışmaları destekleyen uygulamalı çalışmalar, enflasyon hedeflemesi sisteminin enflasyon, faiz ve çıktı miktarı gibi makroekonomik değişkenlerin geliştirilmesinde oldukça önemli olduğu ortaya koymaktadır (Kadria \& Aissa, 2014: 1077). Enflasyon hedeflemesinin makroekonomik değişkenler üzerindeki etkisi, aynı değişkenlere odaklanmış olan maliye politikasının, enflasyon hedeflemesi ile birlikte kullanılmasının gerekliliğini ortaya koymaktadır. Enflasyon hedeflemesi stratejisinin odağında fiyat istikrarının sağlanması ve sürdürülebilmesi bulunmaktadır. Maliye politikaları açısından temel amaçlardan biri olan mali disiplinin sağlanması da benzer şekilde fiyat istikrarının gerçekleşmesi ve sürdürülebilmesine katkı sunmaktadır.

Esasen Türkiye'de 2002 yılında kamuoyuna açıklanmadan örtük enflasyon hedeflemesi şeklinde uygulanan rejimin, 2006 yılının başından itibaren açık enflasyon hedeflemesi şeklinde uygulanmasının arkasında, 10.12.2003 tarihli 5018 sayılı Kamu Mali Yönetimi ve Kontrol Kanunu üzerinde, Avrupa Birliği müktesebatına uygun hale getirilmesi amacıyla 22.12.2005 tarihli 5436 sayılı Kanun ile yapılan değişikliklerin yapılması yatmaktadır. 5018 sayılı Kanun ile yapılan köklü değişikliklerin söz konusu kanunun ruhunu yansıtacak şekilde yürürlüğe girmesi ancak 2006 yılının başında mümkün olabilmiştir. Kamu Mali Yönetimi ve Kontrol Kanunu ile ulaşılmak istenen amaçlardan birisi kaynakların stratejik önceliklere dağıtımının sağlanması ile kamu hizmetlerinin sunumunda çıktı odaklı anlayışla etkinliğin arttırılması ve hesap verebilirlik ve mali saydamlık anlayışının yerleşmesi ile mali disiplinin sağlamasıdır. Bu bağlamda 5018 sayılı Kanun'un bu amaçları içinde barındıracak şekilde hayata geçmesinin 2006 yılından itibaren başlaması, enflasyon hedeflemesi sisteminin kamuoyuna ilan edilerek açık bir şekilde ortaya konmasını da geciktirmiştir. 
Davig ve diğerleri (2011) anlamlı bir maliye politikası olmaksızın, enflasyon hedeflemesinin sağlanmasının zor olacağını belirtmiştir (Davig vd., 2011: 46). Svensson (1996), enflasyon hedeflemesi sisteminin uygulanabilirliğine ilişkin problemlerden biri olarak, para politikası dışında enflasyon üzerinde etkili olan araçları göstermiştir (Svensson, 1997: 1113). Enflasyon hedeflemesi sisteminin etkinliği için koordinasyonun önemi büyüktür, zira enflasyon hedefinin tutturulamaması politika uygulayıcısı olarak merkez bankasının hesap verebilirliğini olumsuz etkileyecektür (Meriç \& Bülbül, 2013: 291). Bütün bu değerlendirmelerden sonra enflasyon hedeflemesi sisteminin tek başına para politikası ile ilgili olmadığı, enflasyonu etkileyen farklı araçların da bulunduğu ve para politikası ile bu araçlar arasında bir uyumun olması gerektiği önemli bir sorun olarak ortaya çıkmaktadır.

Maliye politikası uygulamaları gelir ve harcama boyutları açısından oldukça geniştir. Fiyatlar genel düzeyindeki sürekli artış olarak tanımlanan ve basit bir şekilde ekonomideki toplam talep düzeyinin toplam arzı aşması olarak ifade edilen enflasyon ile maliye politikası arasındaki ilişkinin temelinde, maliye politikası uygulamaları ile ekonomideki toplam talep düzeyinin artış yönünde etkilenmemesi bulunmaktadır. Maliye politikası uygulamalarının toplam talep düzeyi üzerindeki etkisini ölçen en önemli gösterge mali disiplindir. Mali disiplinin ile yani belli bir döneme ilişkin olarak kamu gelirlerinin kamu giderlerini karşılaması ile toplam talep üzerinde kamunun etkisi azaltılmış olacak ve enflasyon hedefinin tutturulabilmesine destek olacaktır.

Tablo: 1

Kamu Net Borç Stoku Miktarı ve GSMH'ya Oranı

\begin{tabular}{|c|c|c|}
\hline \multicolumn{3}{|c|}{ Kamu Net Borç Stoku } \\
\hline Yillar & GSMH Oranı & Milyar TL \\
\hline 2007 & 39,9 & 248,4 \\
\hline 2008 & 40 & 268 \\
\hline 2009 & 46 & 309,9 \\
\hline 2010 & 42,3 & 317,8 \\
\hline 2011 & 39,1 & 290 \\
\hline 2012 & 36,2 & 240,6 \\
\hline 2013 & 36,2 & 197,7 \\
\hline 2014 & 34,1 & 177,9 \\
\hline
\end{tabular}

Kaynak: Hazine Müsteşarllğı.

Mali disiplinin göstergesine ilişkin genel olarak kabul edilen görüş birincil açık/fazla, yani faiz dışı fazla/açık kavramıdır. Faiz ödemeleri dışarıda bırakıldığında bütçenin fazla veriyor olması, borçların ödenebilirliği ve kredibilite açısından oldukça önemli bir göstergedir. Elbette mali disiplin faiz dışı fazla ile sınırlandırılamaz, bunun yanı sıra borç stokunun GSMH'ya oranı açısından durumu da mali disiplin açısından bir göstergedir. Ancak çalışmamızın uygulama kısmında kullandığımız Türkiye örneğinde borç 
stoku dikkate alınmamıştır. Bunun temel nedeni Türkiye'de 2006-2014 yılları arasında 2008 küresel kriz dönemi sonrasındaki 2 yıllık artış haricinde toplam kamu net borç stokunun ve GSMH'ya oranının sürekli düşüyor olmasıdır (Tablo 1). Bu durumda borç stokundaki değişimin mali disiplin üzerinde olumsuz bir etkisinin olmadığ fazla, enflasyon hedeflemesi sistemindeki sayısal enflasyon hedefi olarak ortaya konan parasal kurala benzer şekilde, mali disiplinin sağlanmasına yönelik ortaya konan bir mali kuraldır. $\mathrm{Bu}$ iki kuralın makroekonomi üzerindeki etkileri dışında, birbirleri üzerinde oluşturacağı etki, her iki politikanın etkinliğini ortaya koyma açısından oldukça önemlidir.

Enflasyon hedeflemesi sistemini uygulayan para politikası ile maliye politikasının belli bir koordinasyon içinde çalışması ekonomik koordinasyonun en önemli örneklerinden birini oluşturmaktadır. Bu bağlamda enflasyon hedeflemesi sistemine uygun bir maliye politikasının yürütülmesinin, uygulanan sistemin nihai hedefi olan fiyat istikrarına katkı sağlaması beklenmektedir.

\section{Literatür Taraması}

Ekonomik koordinasyona ve daha dar çerçevede para ve maliye politikalarının koordinasyonu ile ilgili olarak oldukça geniş bir uygulamalı literatür bulunmaktadır. Söz konusu çalışmalar içinde, enflasyon hedeflemesi sistemi ve maliye politikasının temel çıktılarından biri olan mali disiplin veya bütçe dengesi arasındaki ilişkiyi ortaya koyan çalışmalarda bulunmaktadır.

Minea ve Tapsoba (2014) 84 ülkenin 1985-2007 dönemine ilişkin olarak verilerini kullanmış ve 84 ülkeden 30'unu oluşturan enflasyon hedeflemesi uygulayan ülkeleri gelişmiş ve gelişmekte olan ülkeler olarak sınıflandırarak, enflasyon hedeflemesi ile mali disiplin arasındaki ilişkiyi ortaya koymaya çalışmışlardır. Mali disiplin göstergesi olarak birincil bütçe dengesini kullanmışlar ve enflasyon hedeflemesi ile mali disiplin arasında pozitif yönlü bir ilişki sonuç elde ettikleri için para maliye politikalarını koordinasyonuna vurgu yapmışlardır.

Kadria ve Aissa (2014) 1990-2010 yılları arasındaki dönem için 20'si enflasyon hedeflemesi kullanan 41 geçiş ekonomisini ele alarak, enflasyon hedeflemesi ile bütçe açığ arasındaki ilişkiyi, eğilim skoru eşleştirme metoduyla (Propensity Score Matching Method) ortaya koymaya çalışmıştır. Çalışmada enflasyon hedeflemesi sisteminin bütçe açığının azaltılmasına önemli bir katkı sunduğu sonucu elde edilmiştir.

Miles (2015) geçiş ekonomilerinde enflasyon hedeflemesinin mali disiplin üzerindeki etkisini panel analizini kullanarak ölçmeye çalışmıştır. Miles (2015) maliye politikasını beş değişken üzerinden ölçtüğü çalışmasında geçiş ekonomilerinde enflasyon hedeflemesinin mali disiplini geliştirme yönünde bir katkı sunmadığı sonucunu elde etmiştir. 
Aktaş ve diğerleri (2010) 1999-2006 yılları arasında Türkiye ekonomisi verilerini kullanarak, para politikası ve maliye politikası arasındaki ilişkiyi ortaya koymaya çalışmış ve maliye politikası değeri olarak borç stoku değerlerini ele almıştır. Çalışmada maliye politikasına ilişkin dinamiklerin, para politikasının etkinliği üzerinde oldukça etkin olduğu sonucu elde edilmiştir.

Tapsoba (2010) panel veri analizini kullanarak 22 tanesi enflasyon hedeflemesi sistemini kullanan ülke olmak üzere 58 ülkenin 1980-2003 yılları arsındaki verilerine dayanarak enflasyon hedeflemesinin mali disiplin üzerindeki etkisini ortaya koymaya çalışmıştır. Tapsoba (2010) enflasyon hedeflemesinin gelişmekte olan ülkelerde mali disiplin üzerinde pozitif etkiye sahip olduğu sonucunu elde etmiştir.

Combes ve diğerleri (2014) gelişmiş ve gelişmekte olan ülkelerin 1990-2009 yılları arsındaki verilerini kullanarak yaptıkları çalışmada, enflasyon hedeflemesi ve mali kuralların, enflasyon ve mali davranışlar üzerindeki etkisini açıklamaya çalışmışlardır. Çalışma ile mali kuralların ve enflasyon hedeflemesinin kombinasyonunun, makroekonomik performansın sağlanması bakımından oldukça önemli olduğu sonucuna ulaşılmıştır.

Lucotte (2012) 19 tanesi enflasyon hedeflemesin sistemini kullanan ülke olmak üzere 59 ülkenin 1980-2009 yılları arsındaki verilerini kullanarak yaptığı çalışmada, merkez bankasının bağımsızlığı ve düşük enflasyon hedefi ile kullanılan enflasyon hedeflemesinin senyoraj gelirlerini azaltması ve bu azalmanın vergi gelirleri üzerinde arttırıcı yönce bir baskı oluşturup oluşturmayacağını ortaya koymaya çalışmıştır. Çalışma sonucunda enflasyon hedeflemesinin vergi gelirleri üzerinde oldukça önemli düzeyde pozitif etkiye sahip olduğu belirtilmiştir.

Enflasyon hedeflemesi ve mali disiplin ile doğrudan ilgili olan söz konusu çalışmaların yanı sıra, enflasyon hedeflemesinin etkinliğini ve etkinliğin sağlanması için maliye politikasının gerekliliğine vurgu yapan çalışmalar bulunmaktadır. Ancak burada doğrudan enflasyon hedeflemesi ve mali disiplin ilişkisine vurgu yapan çalışmalar ele alınmış ve çalışmamızın uygulama kısmı buna odaklanmıştır.

\section{Veri ve Yöntem}

Çalışmanın geniş anlamda bakış açısı ekonomik koordinasyon olmakla birlikte, dar anlamda odak noktası enflasyon hedeflemesi sistemi ile mali disiplin arasındaki ilişkinin vurgulanmasıdır. Çalışmada Türkiye'de mali disiplinin göstergesi olarak faiz dişı fazla/açık ile enflasyon hedeflemesi arasındaki ilişki zaman serisi ve Granger nedensellik yöntemiyle analiz edilmektedir. Bu amaçla, Türkiye için 2006-2014 yılları arasında hazine müsteşarlığı 
tarafından hazırlanan aylık faiz dışı fazla (birincil fazla) ve merkez bankası tarafindan yayınlanan aylık enflasyon verileri kullanılmıştır. Hedeflenen enflasyondan sapmalar, merkez bankası tarafindan yayınlanan enflasyon hedef rakamları ile aylık enflasyon rakamları karşılaştırılarak tarafımızdan hazırlanmıştır. Çalışmada kullanılan değişkenler Tablo 2'de gösterilmektedir.

Tablo: 2

Değişken Tanımları

\begin{tabular}{|l|l|l|}
\hline Değişken & Tanımı & Kaynak \\
\hline fdf & Faiz dışı fazla (milyon TL) & Hazine Müsteşarlığı \\
\hline enf & Hedeflenen enflasyondan sapma & Merkez Bankası \\
\hline
\end{tabular}

Enflasyon hedeflemesi ve mali disiplin arasındaki ilişkinin otaya konmasına yönelik çalışmada kullanılan model aşağıdaki şekilde gösterilmektedir:

$$
\begin{aligned}
& f d f=\alpha_{0}+\beta_{1} e n f+u_{t} \\
& e n f=\phi_{0}+\partial_{1} f d f+\varepsilon_{t}
\end{aligned}
$$

Zaman serileriyle nedensellik olup olmadığı araştırılırken ilk olarak serilerin mevsimsellik taşıyıp taşımadığına bakılmaktadır. Çalışmada kullanılan değişkenlerden faiz dışı fazla mevsimsel özellik taşıdığı için census X12 yöntemiyle mevsimsellikten arındırılmıştır. İkinci aşamada zaman serilerinin durağanlık göstermeleri önemlidir. Bir zaman serisinin ortalaması ile varyansı zaman içinde değişmiyor ve iki dönem arasındaki ortak varyansı bu ortak varyansın hesaplandığı döneme değil de yalnızca iki dönem arasındaki uzaklığa bağlı ise seri durağandır (Gujarati 1999: 713). Ekonometrik testlerin çoğu için durağan seri varsayımı nedeniyle, durağan olmayan regresörlerin varlığı durumunda birçok standart testi geçersiz olacaktır. Bu nedenle çalışılacak serilerin öncelikle durağanlığının test edilmesi gerekmektedir.

\section{Analiz Sonuçları}

Bir zaman serisinin durağan olup olmadığına ilişkin olarak en çok kullanılan yöntem, birim kök testleridir. Birim kökün varlığına ilişkin olarak Dickey Fuller (1979) ve Genişletilmiş Dickey Fuller (1981) (Augmented Dickey Fuller) testleri hata terimlerinin bağımsız ve aynı dağılıma sahip oldukları varsayımı üzerine kurulmuştur. 
Dickey-Fuller testi hata terimlerinin istatistiksel olarak bağımsız ve sabit varyanslı olduklarını varsayar. Bu yöntem kullanılırken hata terimleri arasında korelasyon olmadığına ve sabit varyanslı olduklarına emin olmak gerekir. Phillips ve Perron (1988), Dickey ve Fuller'ın (1979) hata terimleri ile ilgili varsayımını genişletmişlerdir.

Serilerin arasında durağanlığı ölçmek amacıyla Dickey-Fuller (1979) tarafindan geliştirilen Genişletilmiş Dickey-Fuller birim kök testi (ADF) ve Phillips-Perron (1988) tarafından geliştirilen Phillips-Perron birim kök (PP) testlerinden yararlanılmıştır.

Tablo: 3

ADF ve PP Birim Kök Test Sonuçları

\begin{tabular}{|l|l|l|}
\hline & ADF (düzey değeri) & PP (düzey değeri) \\
\hline \multirow{3}{*}{ fdf } & $-5.7107^{*}$ & $-11.7581^{*}$ \\
& Kritik Değerler & Kritik Değerler \\
& $\% 1(-3.49)$ & $\% 1(-3.49)$ \\
\hline \multirow{3}{*}{ enf } & $-2.5893^{*}$ & $-2.5473^{*}$ \\
& Kritik Değerler & Kritik Değerler \\
& $\% 1(-3.49)$ & $\% 1(-3.49)$ \\
\hline
\end{tabular}

Not: * değiş̧kenlerin \%1 düzeyinde anlamlllikların göstermektedir.

Birim kök testi sonuçlarına göre serilerin ikisi de durağanlık göstermektedir. Seriler durağan olduğu için eş bütünleşme analizine gerek kalmaksızın değişkenler arasındaki ilişki incelenebilmektedir. Çünkü Granger nedensellik testi için serilerin durağan olması gerekmektedir. İki değişkenden birinin tahmini, diğer değişkenin geçmiş değerleri kullanıldığında o değişkenin geçmiş değerleri kullanılmadığı duruma göre daha başarılı ise ilk değişken diğerinin nedenidir. Ĕger iki değişkende de aynı durum söz konusuysa iki taraflı nedensellik söz konusu olmaktadır (Granger, 1988: 554).

Granger nedensellik testinde ilk olarak bağımlı değişkenin gecikmeli değerleri daha sonra bağımlı değişkenin optimal gecikmelerinin olduğu model içerisinde, bağımsız değişkenin optimal gecikme uzunluğu belirlenmektedir. Son olarak ise F testi ile iki zaman serisi arasında Granger nedensellik ilişkisi olup olmadığına bakılmaktadır.

Tablo 4'te mali disiplin değişkeni olarak ele aldığımız faiz dışı fazla değiş̧keniyle enflasyon hedeflemesini gösteren hedeften sapma değişkenleri arasındaki ilişki Granger nedensellik yöntemiyle incelenmektedir. Çalışmanın sonucunda faiz dışı fazla ve enflasyon hedefinden sapma değişkenleri arasında iki yönlü ilişki ikinci gecikmeli dönemde yani 2 aylık süreçte ortaya çıkmaktadır. Yani mali disiplin enflasyon hedeflemesini etkilerken, enflasyon hedeflemesi de mali disipline neden olmaktadır. 


\section{Tablo: 4}

\section{Granger Nedensellik Testi Sonuçları}

\begin{tabular}{|l|l|l|}
\hline Nedensellik Yönü & F istatistiği & Prob \\
\hline Mali disiplin/Enflasyon hedeflemesi & 5.051 & 0.0081 \\
\hline Enflasyon hedeflemesi/Mali disiplin & 4.9287 & 0.0091 \\
\hline
\end{tabular}

\section{Sonuç}

Ekonomik koordinasyonun nihai hedefi, makro değişkenler üzerinde etkili olan politikaların koordinasyonu yoluyla sosyal refahın arttırılabilmesidir. Temel iki politika olarak para ve maliye politikalarının koordinasyonunun sağlanması ile her iki politikanın etkinliğinin arttırılması ve her iki politika yoluyla sosyal refah üzerinde ortaya çıkacak etkinin maksimize edilmesi amaçlanmaktadır. Politikalar arasında yaşanabilecek amaçlar arası veya araçlar arası çatışmaların önlenmesi ile her iki politikanın etkinliğinin artması beklenmektedir.

Çalışmada 2006-2014 yılları arsında Türkiye'de aylık faiz dışı fazla ve enflasyon hedefinden saplamalar kullanılmıştır. Mali disiplinin göstergesi olarak kabul ettiğimiz faiz dışı fazla ile enflasyon hedeflemesi arasında iki yönlü etki elde edilmiştir. Teorik olarak enflasyon hedeflemesi sisteminin gerekliliklerinden biri olarak kabul edilen mali disiplinin sağlanması hususu çalışmamızın sonuçları tarafından desteklenmektedir. Buna bağlı olarak Türkiye'de enflasyon hedeflemesi para otoritesi ve maliye politikasını elinde bulunduran hükümet tarafından belirlenmektedir ve çalışmamızda elde ettiğimiz enflasyon hedeflemesi ile mali disiplin arasındaki güçlü ilişki, her iki uygulamanın devam ettirilmesinin faydalı olacağını göstermektedir. Mali disiplinde ortaya çıkacak bir gevşeklik, para politikası rejimi olarak ortaya konan enflasyon hedeflemesinin başarısını olumsuz etkileyecektir.

Mali disiplinin olumsuz sonuçları ekonomide talep cephesinde bir artış ortaya çıkaracak, talepteki artış ile birlikte enflasyon yükselecek ve temel politika aracı olarak kullanılan kısa vadeli faiz oranlarının artmasına neden olacaktır. Faiz dışı fazla hedefinin devam ettirilmesi kamu net borç stokunu olumlu yönde etkilerken, bir yandan merkez bankasının enflasyon hedefini yakalamasına yardımcı olacaktır.

Türkiye'de para maliye politikası arasındaki uyumun sağlanmasına yönelik en somut kurumlardan olan Ekonomi Koordinasyon Kurulu'nun aldığ kararların uygulamaya geçirilmesinin oldukça önemli olduğu çalışmamız sonucunda elde edilen bulgularlar 1şı̆̆ıında daha net bir şekilde ortaya çıkmaktadır. Ekonomi Koordinasyon Kurulu'nun tavsiye niteliğini aşan bağlayıcı kararlarının makroekonomik performansı arttıracağı düşünülmektedir. 


\section{Kaynakça}

Aktaş, Z. \& N. Kaya \& Ü. Özlale (2010), “Coordination Between Monetary Policy and Fiscal Policy for an Inflation Targeting Emerging Market", Journal of International Money and Finance, 29, 123-138.

Alarslan, M. \& P.A. Erdönmez (2000), "Enflasyon Hedeflemesi”, Bankacılar Dergisi, 35, 14-41.

Amato, J.D. \& S. Gerlach (2002), "Inflation Targeting in Emering Market and Transition Economies: Lessons After a Decade”, Europen Economic Review, 46, 781-790.

Blinder, A. (1982), "Issues in the Coordination of Monetary and Fiscal Policy", Nber Working Paper Series, No. 982.

Combes, J.L. \& X. Debrun \& A. Minea (2014), “Inflation Targeting and Fisca Rules: Do Interactions and Sequencing Matter?" IMF Working Paper, WP/14/89.

Davig, T. \& E.M. Leeper \& T.B. Walker (2001), "Inflation and Fiscal Limit", European Economic Review, 55, 31-47.

Dennis, R. (2010), “The Inflation in Inflation Targeting”, FRBSF Economic Letter, 2010-17, June 7, <http://www.frbsf.org/publications/economics/letter/2010/el2010-17.html>, 10.07.2015.

Dickey, D.A. \& W.A. Fuller (1981), "Distribution of the estimators for autoregressive time series with a unit root", Econometrica, 49, 1057-72.

Dickey, D.A. \& W.A. Fuller (1979), "Distribution of the Estimators for Autoregressive Time Series with a Unit Root", Journal of the American Statistical Association, 74, 427-431.

Eggertsson, G.B. (2010), "Fiscal Multipliers and Policy Coordination", Federal Reserv Bank of New York, <http://www.ny.frb.org/research/economists/eggertsson/preliminary>, 05.07.2015.

Ferre, M. (2008), "Fiscal Policy Coordination in the EMU”, Journal of Policy Modeling, 30, 221 235.

Gosselin, M.A. (2010), “Central Bank Performance under Inflation Targeting”, Working Paper Document de Travil, 2007-18, Bank of Canada, <http://www.bankofcanada.ca/wpcontent/uploads/2010/03/wp07-18.pdf>, 07.07.2015.

Granger, C.W.J. (1988), “Causality, Cointegration and Control”, Journal of Economic Dynamics and Control, 12, 551-559.

Gujarati, D.N. (1999), Temel Ekonometri, (Çev. Ü. Senesen \& G.G.Senesen), İstanbul Literatür Yayınları.

Halaç, U. (2007), “Türkiye'de Para ve Maliye Politikalarının Koordinasyonu”, İktisat, Işsletme ve Finans, 254, 31-47.

Hanif, M.N \& M.F. Arby (2003), "Monetary and Fiscal Policy Coordination”, Munich Personal Repec Archive, No: 10307, <http://mpra.ub.uni-muenchen.de/10307>, 14.06.2015.

Kadria, M. \& M. Aissa (2014), "Implementation of Inflation Targeting and Budget Deficit Performance in Emerging Countries: A Treatment Effect Evaluation", The Journal of Applied Business Research, July/August 2014, 30(4), 1077-1089.

Laurens, B \& E.G. Piedra (1998), “Coordination of Monetary and Fiscal Policies", A Working Paper of International Monetary Fund, IMF. 
Lucotte, Y. (2012), “Adoption of Inflation Targeting and Taz Revenue Performance in Emerging Market Economies: An Empirical Investigation”, Economic Systems, 36, 609-628.

Matei, A \& T. Dogaru (2013) "Coordination of Public Policies in Romania, an Emprical Analysis", Procedia-Social and Behavioral Sciences, 81, 65-71.

Meriç, M. \& D. Bülbül (2013), Mali Yapı, Gazi Kitabevi, Ankara.

Miles, W. (2015), "Do Inflation Targeting Handcuffs Restrain Leviathan? Hard Pegs vs. Inflation Targets for Fisal Discipline in emerging Markets", Applied Economics Letters, 14(9), 647-651.

Minea, A. \& R. Tapsoba (2014), “Does Inflation Targeting Improve Fiscal Discipline?”, Journal of International Money and Finance, 40, 185-203.

Nordhaus, W.D. (1994), "Policy Games: Co-ordination and Independence in Monetary and Fiscal Policeis", Brookings Papers on Economic Activity, 2, 139-216.

Phillips, P.C.B. \& P. Perron (1988) “Testing for a unit root in time series regression”, Biometrika, 75, 335-346.

Sherwin, M. (2000), "Institutional Frameworks for Inflation Targeting", Reserve Bank of New Zealand: Bulletin, 63(4), 28-34.

Svensson, L.E.O. (1997), "Inflation Forecast Targeting: Implementing and Monitoring Inflation Targets”, European Econmic Review, 41 (6), 1111-1146.

Şahin, Ö.U. (2014), “Türkiye'de Enflasyon Hedeflemesinin Kamu Cari (Tüketim) Harcamalarına ve Ç1ktı Açı̆̆ına Etkisi”, Journal of Life Economics, 2/2014, 115-124.

Tapsoba, R. (2010), “Does Inflation Targeting Improve Fiscal Discipline? An Empirical Investigation", CERDI, Etudes et Documents. 